\title{
SPATIAL HETEROGENEITY OF THE EFFECTS OF HUMAN ACTIVITIES ON ECOSYSTEM HEALTH OF A COASTAL TOURISM CITY - A CASE STUDY OF RIZHAO, CHINA
}

\author{
$\mathrm{LI}, \mathrm{J} .{ }^{*}-\mathrm{SHEN}, \mathrm{W} .{ }^{2,3}$

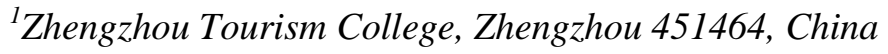 \\ ${ }^{2}$ College of Environment and Planning, Henan University, Kaifeng 475004, China \\ ${ }^{3}$ Key Laboratory of Geospatial Technology for Middle and Lower Yellow River Region, Henan \\ University, Kaifeng 475004, China \\ ${ }^{*}$ Corresponding author \\ e-mail: lijuan05@126.com
}

(Received $1^{\text {st }}$ Feb 2021; accepted $9^{\text {th }}$ Apr 2021)

\begin{abstract}
Under the background of rapid urbanization, increasingly intensive human activities have seriously affected the health of the regional ecosystem, which as a whole is facing potential risk from structural damage to functional disorder. Therefore, an in-depth study of the spatial heterogeneity of the effects of human activities on ecosystem health is of great significance for regional environmental management and sustainable development. Taking the typical tourist city in China - Rizhao as the subject of the study, this paper used VORS model, spatial autocorrelation model, global regression model and geographically weighted regression model to quantitatively analyze the spatiotemporal evolution of the ecosystem health and the spatial heterogeneity of impacts of human activities on ecosystem health in Rizhao. The results show that the ecosystem health level of Rizhao City showed a significant spatial differentiation pattern from 1990 to 2018. The impact of human activities on ecosystem health in the study area has spatial heterogeneity. The built-up areas, central basins and coastal landscape belts of districts and counties are greatly affected by land urbanization, population urbanization and tourism activities. The agricultural areas of the plain and the areas around the built-up areas are greatly affected by agricultural activities and environmental pollution. Due to the spatial heterogeneity of the impact of driving factors on ecosystem health, spatial differences can be taken into account in the formulation of environmental management policies, so as to make the regulation and control countermeasures more targeted.
\end{abstract}

Keywords: ecosystem services, human activity, driving factors, geographically weighted regression model

\section{Introduction}

With the continuous growth of the global population and as the intensity of economic activities continues to increase, human control and influence over the global ecosystem also rises (Pimm et al., 2014; Haddad et al., 2015; Chase et al., 2020). According to the Millennium Ecosystem Assessment report, the natural environmental resources of the earth have been exhausted, and $60 \%$ of the ecosystems have been degraded to varying degrees, for which human activities are the main cause (Ma, 2005; Jin et al., 2020). Ecosystems as a whole face potential risks from structural damage to functional disorders; and the decline in the level of ecosystem health and the sustainable supply of ecosystem services has a far-reaching impact on human well-being and ecological security (Costanza et al., 2017). After the reform and opening up, China's tourism industry has experienced a sustained and rapid development, cultivated the basic tourism industry structure and market framework, and is stepping into the level of a big 
country in the world. However, the industrial attribute of environmental support and resource consumption determines that there is an opposite and unified dual contradiction between the tourism destination and the ecological environment (Qin and Cheng, 2019). The development of tourism will produce three major dynamic effects, namely, the power of direct consumption, the power of industrial development and the power of urbanization, which will lead to the bearing pressure of urban resources (land resources, energy, material resources) and drastic land cover changes, and then lead to a series of eco-environmental problems ( $\mathrm{Li}, 2020)$. As tourism is an industry that is heavily dependent on natural resources, ecological environment and climate change, in turn, the decline of ecosystem health will not be conducive to the sustainable development of tourist cities. Based on this, carrying out ecosystem health assessment of tourist cities and systematically analyzing the spatial heterogeneity of the impacts of human activities on ecosystem health can provide reference for tourist cities to formulate differentiated urban environmental management and ecological regulation policies.

The word "health" originally came from the field of medicine. With the development and improvement of ecological theories such as ecosystem ecology and landscape ecology, foreign scholars began to introduce the concept of health into ecosystemrelated research, the concept of ecosystem health began to enter people's field of vision (Su et al., 2010). Subsequently, scholars have carried out a large number of theoretical exploration, method exploration and practical research on ecosystem health.

In terms of the concept and connotation of ecosystem health, the connotation of "health" is the core issue, difficulty and controversial point of the conceptual framework of ecosystem health. Costanza and Rapprot proposed two mainstream viewpoints reflecting the concept and connotation of ecosystem health (Yan et al., 2016). Rapport and Maffi (2011) proposed that ecosystem health refers to the ability of ecosystems to self-organize, self-maintain and self-restore external pressure on a time scale. At the same time, a healthy ecosystem can provide necessary material supplies and ecosystem services for human survival. Costanza (2012) considered that a healthy ecosystem is active, stable and sustainable, and it can maintain its organization and autonomy over time. In the follow-up, many scholars have supplemented and improved the previous studies (Peng et al., 2017; He et al., 2019). For example, Yan et al. (2016) proposed that a healthy ecosystem comprises integrated and stable inner structures and processes, and the ability to develop its function on a larger, spatiotemporal scale, while maintaining a normal element and energy exchange with the outer system. Xiao et al. (2019) proposed that ecosystem health refers to the ability of ecosystems to self-organize, self-maintain and recovery to pressure in temporal scale, and maintaining a healthy ecosystem is essential to ensure regional sustainable development, because a healthy ecosystem can provide material basis and ecological services for human survival.

In terms of evaluation methods of ecosystem health, because ecosystems are complex, dynamic and cannot be measured directly, performance indicators must be used to evaluate different aspects of ecosystem health. In the process of indicator selection, it must be guided by a considered framework and related metrics (Logana et al., 2020). The evaluation models mainly include the following: vigor-organizationresilience model (VOR) (Kang et al., 2018), pressure-state-response model (PSR) (Shen et al., 2020), driving force-pressure -state-influence-response model (DPSIR) (Wang et al., 2013), subsystem model (Zeng et al., 2016; Su et al., 2019), vigor-organizationresilience-ecosystem services model (VORS) (He et al., 2019; Shi et al., 2020). Among 
them, PSR model and DPSIR model emphasize the causal relationship between human and environment, focusing on the assessment of ecosystem status and external disturbances (Sun et al., 2016; Liu et al., 2017). However, due to too much emphasis on the logical relationship within the evaluation framework, the evaluation indexes of each criterion layer are overlapped and redundant. In addition, the model also ignores the changes of the overall landscape pattern of the ecosystem and the ecosystem services (He et al., 2019). The subsystem model focuses on the assessment of specific aspects of the ecosystem, such as socio-economic, resource, population development and management, while neglecting the change of the overall landscape pattern of the ecosystem and the ecosystem services. The VOR evaluation model was first put forward by Rapport et al. (1998, 1999) and Costanza et al. (1999), and then it was widely used in regional ecosystem health assessment (Bebianno et al., 2015; Kang et al., 2018; Meng et al., 2018; Liao et al., 2018). The advantage of this model is that it can fully reflect the integrity and stability of the structure and function of the ecosystem, the ability of selforganization and self-recovery in the face of pressure, as well as the changes of the overall landscape pattern. Compared with VOR model, VORS model takes into account the supply of ecosystem services (Shi et al., 2020), which makes the evaluation results more accurate and scientific.

In recent years, the driving factors of ecosystem health have been gradually concerned by landscape ecologists and geographers, and the related research results have gradually increased. From the classification of driving factors, it is mainly divided into natural environment and human activity factors (Chi et al., 2018). He et al. (2019) and Shen et al. (2020) systematically analyzed the comprehensive effects of natural factors (meteorology, topography and geology, resource endowment) on ecosystem health. Some scholars have discussed the effects of single human activity factor on ecosystem health, such as urbanization, environmental pollution (Chi et al., 2018), human interference index (Shi et al., 2020), water resources development and utilization activities. The research methods of driving factors usually use regression model (Bebianno et al., 2015), principal component analysis (Bebianno et al., 2015), correlation analysis (Bae et al., 2010), GeoDetector model (He et al., 2019; Shen et al., 2020). Generally speaking, the research on the driving factors of ecosystem health still has the following two deficiencies: first, there have been many studies on the impact of single human activity factors on ecosystem health, but there is a lack of systematic research on a variety of human activity factors. Second, there is a lack of research on the spatial heterogeneity of the impact of human activities on ecosystem health. Compared with the traditional analysis methods of influencing factors, the geographically weighted regression model (GWR) is a more comprehensive statistical method. It can not only analyze the positive and negative relationship and significance between influencing factors and ecosystem health, but also analyze the spatial heterogeneity of each influencing factor on ecosystem health, which is lacking in other studies. Based on this, this paper uses GWR model to systematically analyze the spatial heterogeneity of the impact of human activities on ecosystem health.

Based on multi-source data and GIS and RS techniques, this study quantitatively analyzed the spatio-temporal pattern of ecosystem health in Rizhao City, China. Then, the GWR was used to explore the spatial heterogeneity of the impact of human activity factors on ecosystem health. In order to provide reference for tourist cities to formulate differentiated urban environmental management and ecological regulation and control policies. The steps of this study are as follows: (1) Firstly, the evaluation index of grid 
unit was calculated quantitatively by using RS and GIS technology and related software (ArcGIS 10.3, Fragstats 4.2). (2) Secondly, the VORS model was used to analyze the spatiotemporal characteristics and spatial change trend of ecosystem health in the study area from 1990 to 2018 (The time nodes of the study were 1990, 1995, 2000, 2005, 2010, 2015 and 2018), and the spatial autocorrelation model was used to analyze the spatial agglomeration effect of ecosystem health. (3) The global regression model and GWR model were used to comprehensively analyze the spatial heterogeneity of the impacts of human activities on ecosystem health. Our research is of great significance for urban environmental management and sustainable development of tourism. The aim of this study is to systematically evaluate the level of ecosystem health in tourist cities, accurately describe the spatiotemporal pattern of ecosystem health in the study area, and analyze in detail the spatial heterogeneity of the effects of human activities on ecosystem health in tourist cities. Furthermore, it can provide reference for tourist cities to formulate detailed ecological control measures and strategies.

\section{Materials and Methods}

\section{Study Area}

The Rizhao City is located on the coast of the Yellow Sea (Fig. 1) in southeastern Shandong Province, China. The city has a land area of 5358.57 square kilometers, a coastline of 168.5 kilometers and a sea area of 6000 square kilometers. Rizhao city is a famous coastal ecological, livable and tourist city in China, which has won the United Nations Human Habitation Award for its excellent environment, as well as a modern port city and port-adjacent industrial base. However, in recent years, due to the rapid development of tourism, urbanization and port industry, tourism development activities, industrial development activities and pollution emissions have caused a series of ecoenvironmental problems, such as surface landscape change, environmental pollution and ecosystem degradation. This has seriously affected the health of the regional ecosystem. Therefore, this city is a typical case to study the evolution of tourism destination ecosystem health and the impact of human activities on it.

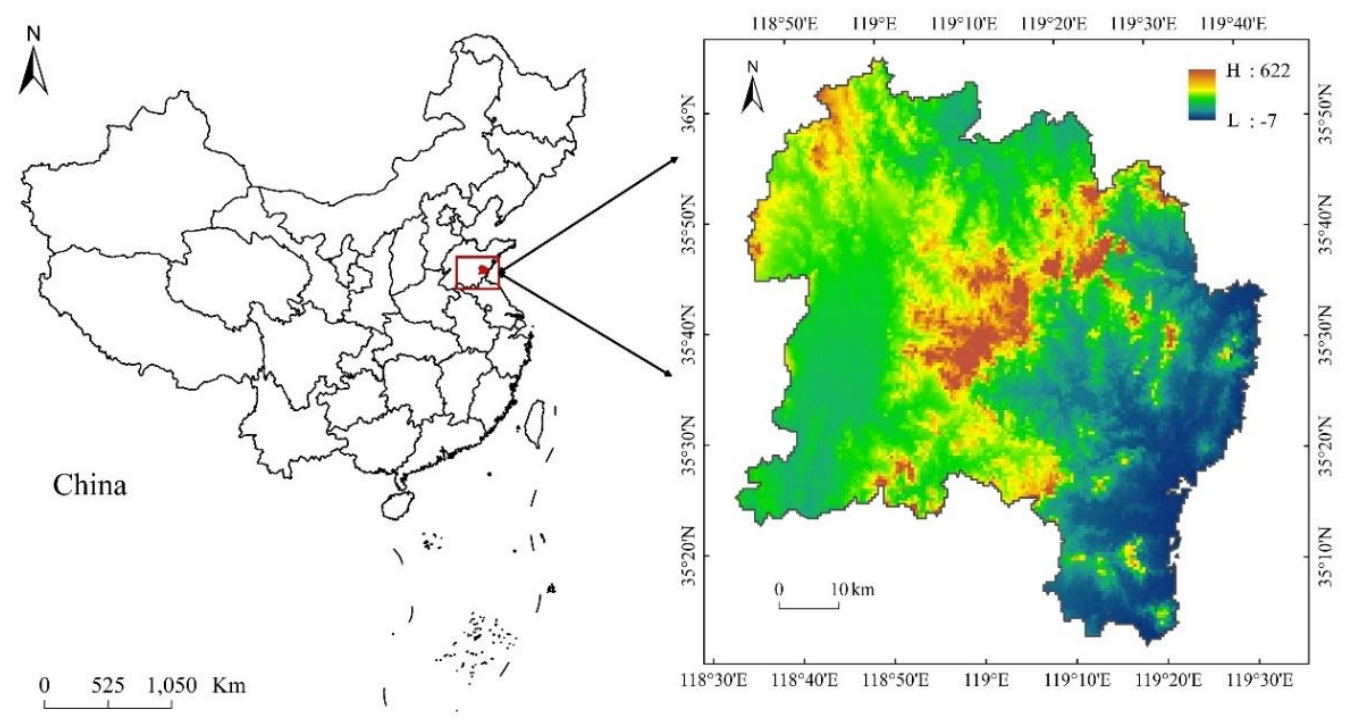

Figure 1. Geographical location of the study area 


\section{Data Sources}

In this study, the vector boundary of the study area, land use raster data with a resolution of 30 meters (data accuracy 94.3\%), point of information (POI), elevation, GDP and population spatial distribution grid data (Table 1) are all come from Data Center for Resources and Environmental Sciences, Chinese Academy of Sciences (RESDC). The annual PM2.5 (fine particulate matter) kilometer grid data is derived from NASA's EarthData website, which removes fine ground particles from dust and sea salt, cross-verification shows that the estimated values at the verification points are highly consistent with the measured values $\left(\mathrm{R}^{2}=0.81\right.$ ) (Zhang and Cao, 2015), and the accuracy is good. Based on the Google Earth Engine (GEE) platform, the reading of Landsat series satellite image data and the stitching of low cloud cover images are realized, and then the annual maximum value of normalized difference vegetation index (NDVI) is calculated by using the maximum value composite method (MVC) (Hu et al., 2020). In this paper, $2 \mathrm{~km}$ grid is used as the basic evaluation unit to calculate the ecosystem health level and influencing factors of all research units. ArcGIS10.3 and Fragstats 4.2 software were used to process the data.

Table 1. List of research data used in the study

\begin{tabular}{|c|c|c|c|c|}
\hline Data name & Data type & Time & $\begin{array}{c}\text { Spatial } \\
\text { resolution }\end{array}$ & Source \\
\hline Study area boundary & Vector data & - & - & http://www.resdc.cn \\
\hline Land use data & Raster data & $\begin{array}{c}1990 / 1995 / 2000 / 2005 / 2010 / \\
2015 / 2018\end{array}$ & $30 \mathrm{~m}$ & http://www.resdc.cn \\
\hline $\begin{array}{l}\text { Normalized difference } \\
\text { vegetation index }\end{array}$ & Raster data & $\begin{array}{c}1990 / 1995 / 2000 / 2005 / 2010 / \\
2015 / 2018\end{array}$ & $250 \mathrm{~m}$ & $\begin{array}{c}\text { https://www.earthengine.go } \\
\text { ogle.org/ }\end{array}$ \\
\hline Elevation & Raster data & 2015 & $90 \mathrm{~m}$ & http://www.resdc.cn \\
\hline $\begin{array}{l}\text { GDP spatial distribution } \\
\text { date }\end{array}$ & Raster data & 2015 & $1 \mathrm{~km}$ & http://www.resdc.cn \\
\hline $\begin{array}{c}\text { Population spatial } \\
\text { distribution date }\end{array}$ & Raster data & 2015 & $1 \mathrm{~km}$ & http://www.resdc.cn \\
\hline POI & Vector data & 2015 & - & http://www.resdc.cn \\
\hline $\begin{array}{l}\text { Global Annual PM2.5 } \\
\text { Grids }\end{array}$ & Raster data & 2015 & $1 \mathrm{~km}$ & $\begin{array}{c}\text { https://search.earthdata.nas } \\
\text { a.gov/search }\end{array}$ \\
\hline
\end{tabular}

\section{Ecosystem Health Assessment}

Ecosystem health refers to the sustainability, self-maintenance ability and the stability of providing ecosystem services of ecosystem chimera under a certain spatiotemporal scale (Costanza et al., 2012). A healthy ecosystem should not only have the ability to provide stable ecosystem services for human beings, but also have the ability of sustainable development to maintain the integrity of its structure and function (Santos et al., 2001; Xu et al., 2010; He et al., 2019; Sun et al., 2019). The VORS model is developed on the basis of VOR evaluation model. The advantage of this model is that it can fully reflect the integrity and stability of ecosystem structure and function, the ability of self-organization and self-recovery under pressure, and the ability of 
ecosystem services. Therefore, it has been widely used in ecosystem health research in recent years (Shi et al., 2020; Xiao et al., 2020). The evaluation index of ecosystem health includes four parts: vigor $(\mathrm{V})$, organization $(\mathrm{O})$, resilience $(\mathrm{R})$ and ecosystem services (S). The ecosystem health index formula is expressed as follows:

$$
\begin{gathered}
E H I=\sqrt{P H I \times E S} \\
P H I=\sqrt[3]{E V \times E O \times E R}
\end{gathered}
$$

where EHI, PHI and ES represent regional ecosystem health index, health level of ecosystem physical, and ecosystem service capacity respectively. EV, EO and ER represent ecosystem vigor, ecosystem organization and ecosystem resilience, respectively.

Ecosystem vigor (EV) describes the metabolism or primary productivity of ecosystem. NDVI is closely related to vegetation growth and net primary productivity, and has been widely proved to be an effective method to evaluate ecosystem vitality (He et al., 2019; Xiao et al., 2020). Therefore, we choose NDVI to characterize the level of ecosystem vitality. NDVI can be calculated as NDVI= (NIR-RED) / (NIR+RED), NIR and RED are near infrared band and visible red band respectively (Hu et al., 2020).

Ecosystem organization (EO) refers to the stability of ecosystem structure and the number and diversity of relationships among its components (Costanza et al., 2012; Kang et al., 2018). It is mainly measured by landscape heterogeneity and landscape connectivity (He et al., 2019; Xiao et al., 2020). Landscape heterogeneity was usually quantified by Shannon's diversity index (SHDI) and area-weighted patch fractal dimension (AWMPFD) (Peng et al., 2017; He et al., 2019; Xiao et al., 2020). Landscape connectivity includes overall landscape connectivity and patch connectivity of important ecosystems (Peng et al., 2017; He et al., 2019). Landscape fragmentation index (LN) and landscape aggregation index (CONTAG) are usually used to represent the overall landscape connectivity, and patch fragmentation index $(\mathrm{PN})$ and patch cohesion index (CONHESION) of woodland, water and grassland were used to represent the patch connectivity of important ecosystems (He et al., 2019). According to the relative importance, the weights of landscape heterogeneity $(\mathrm{LH})$, overall landscape connectivity (LC), and patch connectivity (PCIE) of important ecosystems were $0.35,0.35$ and 0.3, respectively (He et al., 2019; Xiao et al., 2020).

$$
\left\{\begin{array}{l}
\text { EO }=\text { LH }+ \text { LC }+ \text { PCIE } \\
L H=0.1 \times \text { AWMPFD }+0.25 \times \text { SHDI } \\
L C=0.25 \times \mathrm{FN}+0.1 \times \text { CONTAG } \\
\text { PCIE }=0.07 \times F_{f}+0.03 \times \text { COHESION }_{f}+0.07 \times F N_{w} \\
\quad+0.03 \times \text { COHESION }_{w}+0.07 \times \text { FN }_{g}+0.03 \times \text { COHESION }_{g}
\end{array}\right.
$$

where EO is an ecosystem organization; LH, LC and PCIE are landscape heterogeneity, overall landscape connectivity and patch connectivity of important ecosystems, respectively; AWMPFD is area-weighted patch fractal dimension, SHDI is Shannon's diversity index, $\mathrm{FN}$ is landscape fragmentation index, CONTAG is landscape aggregation index; $F N_{f}, F N_{w}$ and $F N_{g}$ are patch fragmentation indexes of woodland, water and grassland, respectively. COHESION,$C_{f} C_{\text {CHESION }}$ and $\operatorname{COHESION}_{g}$ are patch cohesion indexes of woodland, water area and grassland, respectively.

Ecosystem resilience (ER) reflects the ability of ecosystem to maintain its own structure, function and model in the face of external disturbance (stress). A healthy 
ecosystem should be resilient enough to survive a variety of small-scale disturbances. The calculation formula of ecological resilience index refers to the existing research (Xiao et al., 2019; Shen et al., 2020). Previous studies have shown that ecological resilience is reflected in two aspects: one is the ability to resist external interference; the other is the ability to restore the ecosystem to its original state after serious damage ( $\mathrm{Lu}$ et al., 2014). The degree of these two aspects is measured by resistance coefficient and resilience coefficient respectively. The formula for calculating the ecological resilience index is defined as (Peng et al., 2017; Xiao et al., 2019):

$$
R I=0.6 \times \sum_{i=1}^{5} P_{i} * \text { Resist }_{i}+0.4 \times \sum_{i=1}^{5} P_{i} * \operatorname{Resil}_{i}
$$

where RI is the ecological resilience index, $P_{i}$ is the ratio of the area of the $i$ landscape type to the area of the study unit, and Resist ${ }_{i}$ and $\operatorname{Resil}_{i}$ are the resistance coefficient and resilience coefficient of the $i$ landscape type respectively (Table 2). Xiao et al. (2019) points out that if the development level of the study area is relatively low, more attention should be paid to resistance. In this paper, the level of economic development in the study area is relatively low, so a higher weight value of 0.6 is used to emphasize resistance, and the weight of resilience was 0.4 .

Table 2. The ecosystem resilience coefficient of each landscape type

\begin{tabular}{c|c|c|c|c|c}
\hline Landscape type & Forest land & Grassland & Farmland & Construction land & Water body \\
\hline Resist & 1 & 0.6 & 0.5 & 0.3 & 0.8 \\
Resil & 0.6 & 0.8 & 0.3 & 0.2 & 0.7 \\
\hline
\end{tabular}

Ecosystem services (ES) refers to the services provided by the ecosystem directly or indirectly in the process of interaction with human beings, such as food supply, climate regulation. Through a quantitative way to transform ecosystem services into specific value, that is, the value of ecosystem services. Referring to the Chinese ecosystem service value equivalent factor studied by Xie et al. (2008, 2015), and modifying the ecosystem service value coefficient regionally (Zhang et al., 2020), the ecosystem service value equivalent factor table in the study area was obtained (Table 3). In this paper, the evaluation model proposed by Costanza et al. (1997) was used to calculate the service value of various land use types and the total value of ecosystem services according to Equations (5) and (6).

Table 3. Factor of ecosystem services value per unit area in Rizhao

\begin{tabular}{|c|c|c|c|c|c|c|c|}
\hline \multirow{2}{*}{\multicolumn{2}{|c|}{ Function types }} & \multicolumn{6}{|c|}{ Ecosystem services value/( US dollars per ha(\$/ha)) } \\
\hline & & \multirow{2}{*}{\begin{tabular}{|c|} 
Farmland \\
290.07 \\
\end{tabular}} & \multirow{2}{*}{\begin{tabular}{|c|} 
Woodland \\
95.72
\end{tabular}} & \multirow{2}{*}{\begin{tabular}{|c|} 
Grassland \\
124.73 \\
\end{tabular}} & \multirow{2}{*}{$\begin{array}{c}\text { Water } \\
153.74\end{array}$} & \multirow{2}{*}{\begin{tabular}{|l|} 
Bulit \\
0.00
\end{tabular}} & \multirow{2}{*}{\begin{tabular}{|c|} 
Unused \\
5.80
\end{tabular}} \\
\hline & Food production & & & & & & \\
\hline & Raw material producti & 113.13 & 864.41 & 104.42 & 101.52 & 0.00 & 11.60 \\
\hline \multirow{4}{*}{ Regulating service } & Gas regulation & 208.85 & 1253.10 & 435.10 & 147.94 & 0.00 & 17.40 \\
\hline & Climate regulation & 281.37 & 1180.58 & 452.51 & 597.54 & 0.00 & 37.71 \\
\hline & Water supply & 223.35 & 1186.38 & 440.90 & 5444.60 & 0.00 & 20.31 \\
\hline & Waste treatment & 403.20 & 498.92 & 382.89 & 4307.53 & 0.00 & 75.42 \\
\hline
\end{tabular}




\begin{tabular}{cc|c|c|c|c|c|c}
\hline \multirow{2}{*}{ Supporting service } & $\begin{array}{c}\text { Soil conservation } \\
\text { Biodiversity protection }\end{array}$ & $\begin{array}{c}426.40 \\
295.87\end{array}$ & $\begin{array}{c}1166.08 \\
1308.21\end{array}$ & $\begin{array}{c}649.76 \\
542.43\end{array}$ & $\begin{array}{c}118.93 \\
994.94\end{array}$ & $\begin{array}{c}0.00 \\
0.00\end{array}$ & $\begin{array}{c}49.31 \\
116.03\end{array}$ \\
\hline \multirow{2}{*}{ Cultural service } & Entertainment culture & 49.31 & 603.34 & 252.36 & 1287.91 & 0.00 & 69.62 \\
\hline \multirow{2}{*}{ Total } & 2291.55 & 8156.74 & 3385.11 & 13154.63 & 0.00 & 403.20 \\
\hline
\end{tabular}

$$
\begin{gathered}
E S V_{i}=A_{i} \times V C_{i} \\
E S V=\sum_{i=1}^{n}\left(A_{i} \times V C_{i}\right)
\end{gathered}
$$

where $E S V_{i}$ and $E S V$ are the service value of the $i$ land use type and the total value of ecosystem services respectively; $A_{i}$ is the land area of the $i$ land use type $\left(\mathrm{km}^{2}\right) ; V C_{i}$ is the ecosystem service value per unit area of the $i$ land use type (US dollars $/ \mathrm{hm}^{2} \cdot \mathrm{a}^{-1}$ ).

\section{Spatial Autocorrelation Method}

We use the method of spatial autocorrelation analysis to analyze the spatial agglomeration effect of ecosystem health. Spatial autocorrelation refers to the interdependence of spatial unit attributes in space, and is a way to measure the degree of spatial agglomeration (Xiao et al., 2020; Shen et al., 2020). According to the size of the spatial range, spatial autocorrelation can be divided into global spatial autocorrelation and local spatial autocorrelation. Global spatial autocorrelation measures the degree of spatial correlation of a region as a whole, and it is often measured by Moran's I index. The global autocorrelation formula is:

$$
I=\frac{n}{s_{o}} \frac{\sum_{i=1}^{n} \sum_{j=1}^{n} w_{i j}\left(x_{i}-\bar{x}\right)\left(x_{j}-\bar{x}\right)}{\sum_{i=1}^{n}\left(x_{i}-\bar{x}\right)^{2}}
$$

where $\mathrm{n}$ is the total number of spatial units; $x_{i}$ and $x_{j}$ are the observed values of spatial units $i$ and $j$, respectively; $w_{i j}$ is the spatial weight matrix, which is used to reveal the spatial relations among the elements; and $s_{o}$ is the aggregate of all the spatial weights, $s_{o}=\sum_{i=1}^{n} \sum_{j=1}^{n} w_{i j}$. The range of Moran's I index is [-1,1].

Although global spatial autocorrelation can measure the overall spatial dependence of the observed variables, it ignores the local instability of the space to a certain extent. Therefore, in order to further explore the local spatial correlation features, the local spatial autocorrelation method is introduced to analyze the local spatial autocorrelation features. The specific calculation formula is as follows:

$$
I_{i}=Z_{i} \sum_{i=1}^{n} w_{i j} Z_{j}
$$

where $Z_{i}$ and $Z_{j}$ are the standardized values of spatial units $i$ and $j$, respectively, and $w_{i j}$ is a spatial weight matrix, which is used to reveal the spatial relationship between spatial units.

\section{Classification and Selection of Human Activity Factors}

Human activity was widely recognized as a major factor affecting ecosystem health. Human activities affect the structure and functional integrity of the ecosystem and the supply of ecosystem services through changing the surface cover, discharging pollutants, 
interfering with the growth and reproduction of animals and plants, and changing the material and energy cycle process of the biological chain, thus affecting the ecosystem health level. According to relevant research results, human activities can be divided into urbanization (Xu et al., 2013; He et al., 2019; Xiao et al., 2020), tourism activities, agricultural activities (Wu et al., 2018; Cao et al., 2019), environmental pollution (air, water, soil and light pollution) (Mirsanjari et al., 2020; Häder et al., 2020; Paoletti et al., 2020), ecological restoration, water resources development and utilization activities (south-to-north water diversion project, water conservancy project) (Guo et al., 2018; Ling et al., 2019; Shen et al., 2020). Considering the quantitability and accessibility of the factors, as well as the actual situation of the research, we constructed the index system of human activity factors from four aspects, including urbanization, tourism activities, agricultural activities and environmental pollution (Table 4).

Table 4. Classification index system of human activity factors

\begin{tabular}{c|c|c|c}
\hline Influencing factor & Factors & Code & Indicators \\
\hline \multirow{4}{*}{ Human activity factors } & Urbanization & X1 & Land urbanization \\
& & X2 & Population urbanization \\
\cline { 2 - 4 } & Tourism activities & X4 & Density of tourist scenic spot \\
\cline { 2 - 4 } & Agricultural activities & X5 & Density of cultivated land \\
\cline { 2 - 4 } & Environmental pollution & X6 & PM2.5 concentration \\
\hline
\end{tabular}

The selection of influencing factors is mainly based on the following assumptions: (1) urbanization. Urbanization mainly destroys the surface cover and ecological landscape, interferes with the survival of animals and plants, directly and indirectly affects the structure and function of the ecosystem, and then has a negative impact on the overall ecosystem health level. Urbanization is generally divided into land urbanization, population urbanization and economic urbanization, in which land urbanization represents the overall impact of land cover changes on the ecosystem brought about by urbanization. Population urbanization and economic urbanization represent the impact of land cover changes on ecosystems brought about by urban and rural settlements and various industrial expansion respectively. (2) Tourism activities. Tourism development activities under tourism activities will cause direct damage to the ecosystem; the flow of tourism population and its related food, accommodation and transportation will increase the pressure on the supply of energy resources and the regulation of ecological environment in tourism destinations, and then exert adverse effects on the ecosystem (Sun and Wen, 2019; Sun et al., 2020). In addition, tourism activities promote regional economic development, at the same time, the rapid development of supporting industries (road infrastructure, hotel industry, catering industry) will also further have a negative impact on the ecosystem. (3) Agricultural activities. Agricultural activities destroy the landscape connectivity and aggregation of important elements in the ecosystem (woodlands, grasslands, wetlands, waters) (Chen et al., 2012; Lu et al., 2014), and then have a negative impact on ecosystem health. In addition, soil erosion and environmental pollution caused by agricultural activities also have an important negative impact on ecosystem health (Li et al., 2011; Asumadu-Sarkodie and Owusu, 2017). (4) Environmental pollution. Environmental pollution has direct and indirect harm to regional ecosystem from many aspects, and has a potential negative impact on human well- 
being. The higher the level of comprehensive utilization of resources and environment and the level of sustainable development, the more conducive to the improvement of ecosystem carrying capacity (Khim, 2017; Dou and Zhang, 2019).

\section{The Geographical Weighted Regression Model}

In this study, considering the limitations of the traditional linear regression model in the spatial characteristics of independent variables and their "global" estimation (Yang and Liu, 2014), we comprehensively use ordinary least square (OLS) and GWR model to analyze the overall and local effects of different human activity factors on the ecosystem health. In order to more intuitively reflect the spatial non-equilibrium and its changing trend of the influencing factors of ecosystem health. Assuming a series of observed values of explanatory variables $x_{i j}$ and explained variables $y_{j}(i=1,2, \cdots, m$, $j=1,2, \cdots, n)$, the global regression model is as follows:

$$
Y_{j}=\beta_{0}+\sum_{j=1}^{n} \beta_{j} x_{i j}+\varepsilon_{i}(i=1,2, \cdots, m ; j=1,2, \cdots, n)
$$

where $\varepsilon$ is the error term, $\beta_{0}$ is the regression constant. The geographically weighted regression model extends the traditional linear regression model, and its regression coefficient is no longer the assumed constant $\beta_{0}$ obtained by global information, but is estimated by local regression with the sub-sample data information of adjacent observations, and changes with the change of spatial location, the formula of geographically weighted regression model is as follows:

$$
Y_{i}=\beta_{0}\left(S_{i}, T_{i}\right)+\sum_{j=1}^{n} \beta_{j}\left(S_{i}, T_{i}\right) x_{i j}+\varepsilon_{i}
$$

where $Y_{i}$ is the ecosystem health index of the study unit $i ;\left(\mathrm{S}_{i}, \mathrm{~T}_{i}\right)$ is the central geographical location coordinate of the $i$ unit. $\beta_{j}\left(S_{i}, T_{i}\right)$ is the $j$ regression parameter at the $i$ point, which is determined by the spatial location of the $i$ point. $x_{i j}$ is the sample value of each influencing factor $x_{j}$ at the $i$ point. $\varepsilon_{i}$ is a random error. In the process of model calculation, the modified Akaike information criterion (AICc) was selected to determine the optimal bandwidth (Brunsdon et al., 1999). The regression coefficient of the GWR model is expressed as:

$$
\beta_{j}\left(S_{i}, T_{i}\right)=\left(X^{T} W\left(S_{i}, T_{i}\right) X\right)^{-1} X^{T} W\left(S_{i}, T_{i}\right) y_{i}
$$

where $X$ is the matrix of explanatory variables; $X^{T}$ is the transpose of the explanatory variable; $W\left(S_{i}, T_{i}\right)$ is the spatial weight matrix of observation point $i$.

\section{Results}

\section{Spatio-temporal Pattern of Ecosystem Health}

From 1990 to 2018, the ecosystem health level of the study area showed a significant spatial differentiation pattern. From a detail standpoint, the low-value areas of ecosystem health were mainly distributed in the western plain agricultural area, the central basin, and the built-up area along the southeast coast (Fig. 2). Among them, the plain agricultural area in the northwest was the largest low-value area. The ecosystem health level of the 
surrounding area of built-up area and central basin decreased significantly. The high value areas of ecosystem health were mainly distributed in the central mountainous and hilly areas, as well as the coastal eco-landscape zones in the east and south.
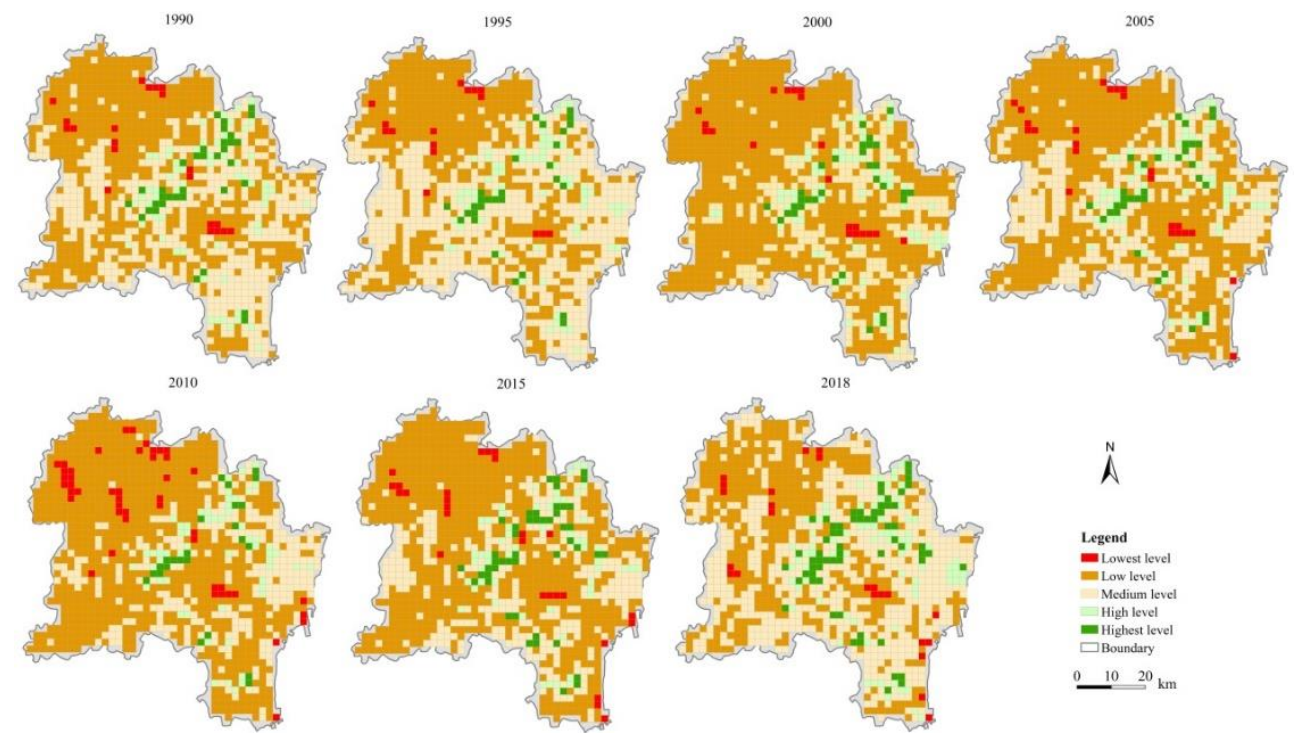

Figure 2. The spatial change of ecosystem health from 1990-2018

From 1990 to 1995, the number of units with increased health index in the study area accounted for $63.25 \%$ of the total units, and the number of units with reduced health index accounted for $36.75 \%$, indicating that the overall health level of the study area had improved (Fig. 3). In detail (Fig. 4), the areas with reduced health level are mainly distributed in the agricultural areas in the north, the built-up areas in the county, and the built-up areas at the prefecture-level city in the southeast. The areas with improved health level are mainly distributed in the mountainous and hilly areas in the middle, and the coastal ecological landscape belt in the east.

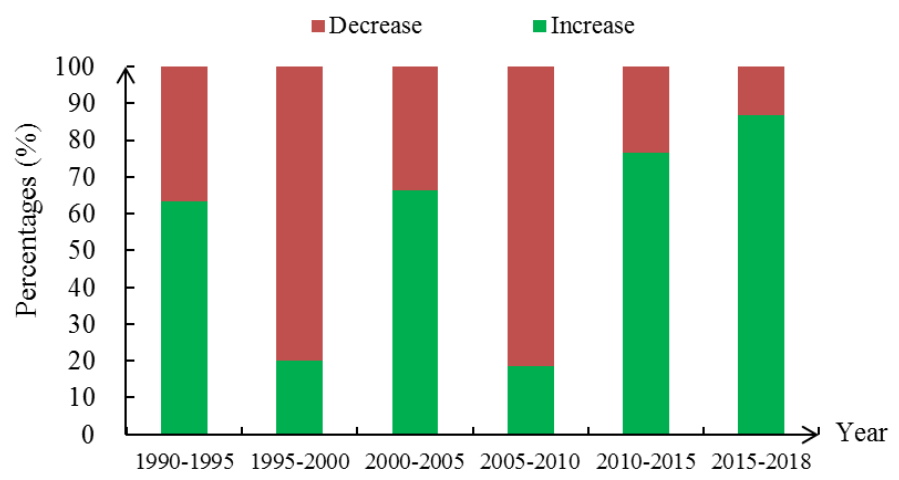

Figure 3. The proportion of increase and decrease in research units from 1990-2018

The period from 1995 to 2010 was the period of rapid development of urbanization and tourism in the study area. In the three periods of 1995-2000, 2000-2005 and 20052010 , the proportion of units with improved health level accounted for $20 \%, 66.32 \%$ and $18.46 \%$ of the total units, while the proportion of units with reduced health level 
was $80 \%, 33.68 \%$ and $81.54 \%$ respectively (Fig. 4). It shows that the overall health level of the study area tends to decline. In detail (Fig. 3), the areas with reduced health level were mainly distributed in the western and northern plains of the study area, as well as in the eastern built-up areas. The expansion of building land and large-scale agricultural activities were the main reasons for the decline of ecosystem health in the northwest plain agricultural area. The central basin is rich in resources and beautiful ecological landscape, the construction of transportation facilities and the rapid development of tourism and related industries have caused drastic changes in land cover.
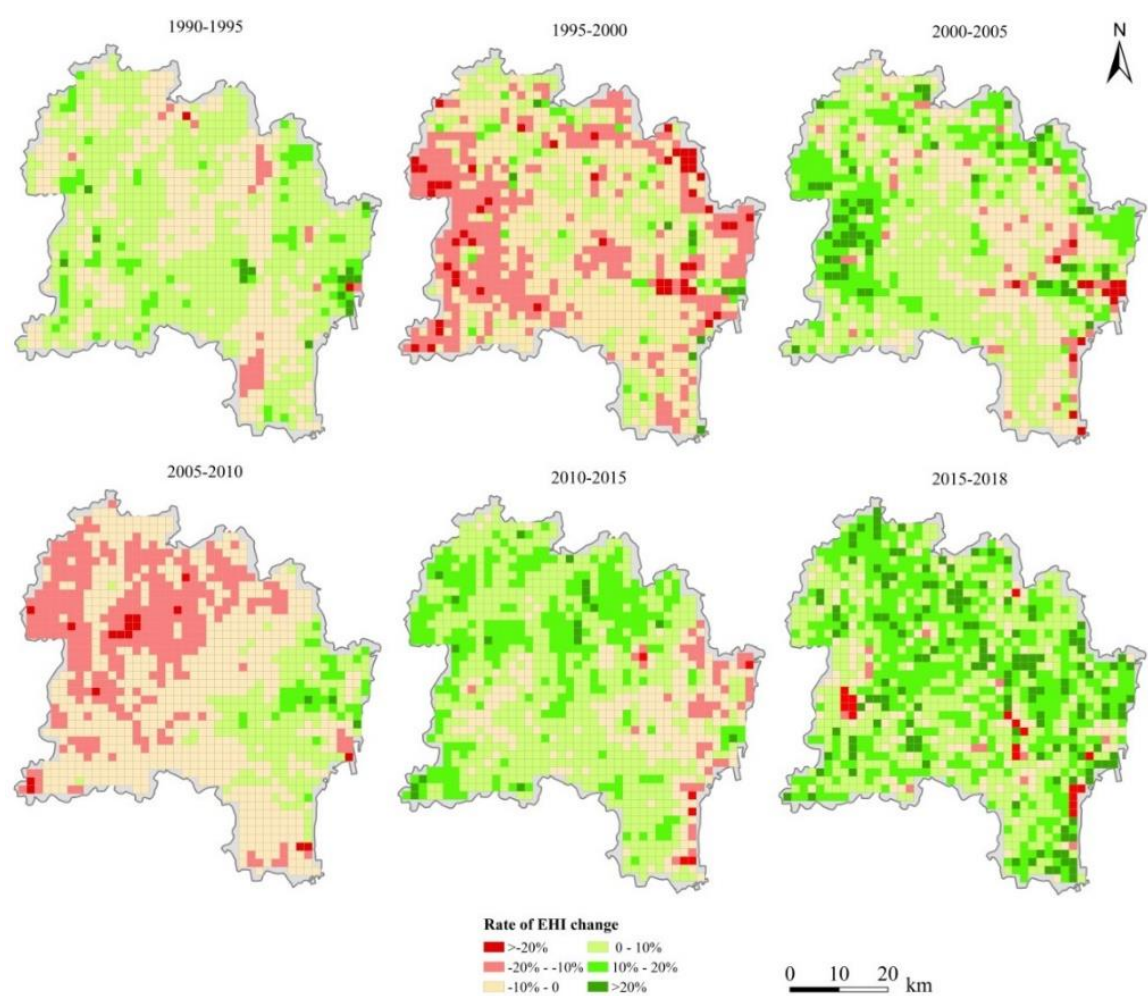

$\stackrel{10 \quad 20}{0} \mathrm{~km}$

Figure 4. The spatial change trend of ecosystem health from 1990-2018

In the two periods of 2010-2015 and 2015-2018, the proportion of the units with improved health level were $76.58 \%$ and 86.84 , respectively, while the proportion of the units with reduced health level was $23.42 \%$ and $13.16 \%$, respectively, indicating that the overall health level of the study area had been improved (Fig. 3). In the context of the gradual slowing down of urbanization, industrial transformation, and implementation of regional eco-environmental protection policies, the health level of most areas in the study area has improved from 2010 to 2018 (Fig. 4). However, the health level has decreased in the eastern coastal areas, the central mountain fringe areas, and the eastern coastal eco-landscape belt areas.

\section{Spatial Agglomeration Characteristics of Ecosystem Health}

We use the spatial autocorrelation method in GeoDa software to analyze the global and local spatial correlation characteristics of ecosystem health. The results of global spatial autocorrelation analysis showed that the global Moran's I index of ecosystem health was positive and passed the significance level test. It shows that there is an obvious spatial 
positive correlation between ecosystem health in Rizhao, that is, the phenomena of high value agglomeration and low value agglomeration are significant (Table 5).

Table 5. Results of global spatial autocorrelation analysis

\begin{tabular}{c|c|c|c|c|c|c|c}
\hline Year & $\mathbf{1 9 9 0}$ & $\mathbf{1 9 9 5}$ & $\mathbf{2 0 0 0}$ & $\mathbf{2 0 0 5}$ & $\mathbf{2 0 1 0}$ & $\mathbf{2 0 1 5}$ & $\mathbf{2 0 1 8}$ \\
\hline Moran's I & 0.467 & 0.471 & 0.473 & 0.455 & 0.504 & 0.459 & 0.473 \\
P-value & 0.001 & 0.001 & 0.001 & 0.001 & 0.001 & 0.001 & 0.001 \\
Z-value & 30.594 & 31.115 & 31.386 & 30.179 & 33.224 & 30.352 & 31.14 \\
\hline
\end{tabular}

Furthermore, we use the local spatial autocorrelation method to analyze the local spatial autocorrelation characteristics of ecosystem health in Rizhao. The high-high concentration areas were mainly distributed in the central mountains and the northeast coastal areas (Fig. 5). Affected by the natural environment (topography) and traffic, the intensity of human activities was low, and the units with high health level tend to gather in space. The low-low concentration areas were distributed in the urban built-up areas, plain agricultural areas and central basins in the northwest. The low-high concentration areas are adjacent to the highhigh concentration area, which were mainly distributed in the surrounding areas of the central mountain area, and these areas were mainly affected by agricultural activities and tourism activities. During the study period, the area of high-high agglomeration areas (urban built-up areas and central basin) showed a trend of expansion. In the northwest, the area of high-high agglomeration area (plain agricultural area) decreased first, then increased, and then decreased again. The low-low agglomeration area in central Rizhao has a tendency to expand to the northeast coastal areas.

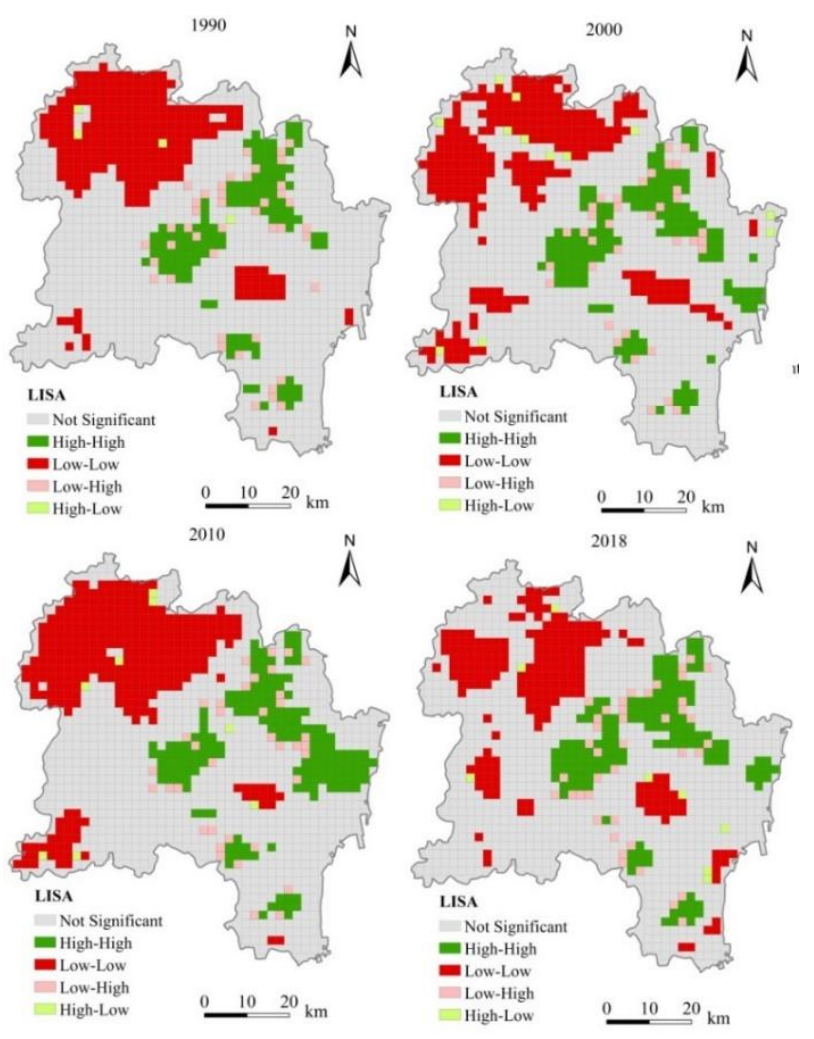

Figure 5. LISA agglomeration map of ecosystem health in Rizhao city from 1990 to 2018 


\section{Spatial Heterogeneity of the Effects of Human Activities on Ecosystem Health}

\section{Global Analysis of Driving Factors Based on OLS Model}

Considering the availability of influencing factors, this study used SPSS software to standardize the variables and indicators of influencing factors in 2015, and then used tolerance and variance inflation factor (VIF) to carry out multiple collinearity test. It is found that the tolerance of all explanatory variables was more than 0.1 and the VIF was less than 10 (Table 6), indicating that there was no multicollinearity between explanatory variables. The results of OLS model analysis (Table 6) show that the model as a whole passed the $1 \%$ significant level test in 2015, and the goodness of fit of the model was $50.3 \%$, respectively, indicating that the selected explanatory variables can better explain the spatial differences of ecosystem health.

Table 6. Result of the OLS model

\begin{tabular}{c|cccc}
\hline \multirow{2}{*}{$\begin{array}{c}\text { Independent } \\
\text { variable }\end{array}$} & Betain & $\mathrm{t}$ & Sig. & VIF \\
\cline { 2 - 5 } Constant term & 0.491 & 36.973 & 0.000 & \\
LUR & -0.063 & -1.761 & 0.068 & 2.710 \\
PUR & -0.112 & -2.790 & 0.005 & 2.093 \\
Tour & 0.236 & 8.117 & 0.000 & 1.300 \\
Farmland & -0.167 & -11.892 & 0.000 & 1.050 \\
PM2.5 & -0.111 & -4.124 & 0.000 & 1.622 \\
R $^{2}$ & & & 0.525 & \\
Adjust R & & 0.503 & \\
F-statistics & \multicolumn{3}{|c}{60.680} \\
Sig. & \multicolumn{3}{c}{0.000} \\
\end{tabular}

The results of model analysis show that the four factors such as population urbanization, tourism activity density, cultivated land density and PM2.5 concentration all pass the $1 \%$ significance level test, and the land urbanization factors pass the $5 \%$ significance level test (Table 6). Among them, the action direction of land urbanization, population urbanization, cultivated land density and PM2.5 concentration was in line with the theoretical expectation, while the action direction of tourism activity density was opposite to the theoretical expectation. Specifically, the factors of land urbanization, population urbanization, cultivated land density and PM2.5 concentration have negative effects on ecosystem health, indicating that the increase of land urbanization rate, population urbanization rate, cultivated land density and PM2.5 concentration reduces the level of regional ecosystem health to a certain extent. The factor of tourism activity density has a positive impact on regional ecosystem health.

\section{Local Analysis of Driving Factors Based on GWR Model}

The GWR model in ArcGIS10.3 was used to conduct a fitting analysis of regional ecosystem health and its influencing factor variables, and five factors including land urbanization, population urbanization, tourism activity density, cultivated land density and PM2.5 concentration were included in the GWR model analysis. As shown in Table 7, the goodness of fit of the model is 0.6194 and the AICC is -2138.61. Comparing the analysis results of OLS model (Table 6) and GWR model (Table 7), it is found that the fitting effect of GWR model is obviously better than that of OLS model. 
Table 7. Test result of the GWR model

\begin{tabular}{c|c}
\hline Model parameter & $\mathbf{2 0 1 5}$ \\
\hline Bandwidth & 18089.79 \\
AICc & -2138.61 \\
$\mathrm{R}^{2}$ & 0.6398 \\
Adjust $\mathrm{R}^{2}$ & 0.6194 \\
\hline
\end{tabular}

Furthermore, the global autocorrelation analysis of the standardized residuals in the analysis results of the GWR model shows that (Table 8), the global Moran's I index of the standardized residuals was 0.0363 and the $\mathrm{Z}$ value was 1.2126 , which does not pass the significance test, indicating that the standardized residuals were randomly distributed and the GWR model was applicable as a whole.

Table 8. Global spatial autocorrelation test for standardized residues

\begin{tabular}{c|ccc}
\hline \multirow{2}{*}{ Year } & \multicolumn{3}{|c}{ Global autocorrelation coefficient } \\
\cline { 2 - 4 } & Moran's $I$ & Z-score & P-value \\
\hline 2015 & 0.0363 & 1.2126 & 0.1182 \\
\hline
\end{tabular}

\section{Spatial Heterogeneity of Driving Factors}

In order to demonstrate the spatial heterogeneity of the effects of influencing factors on the regional ecosystem health, the regression coefficients of land urbanization, population urbanization, tourism activities, agricultural activities and environmental pollution factors were spatially visualized with the help of ArcGIS10.3 software (Fig. 6).

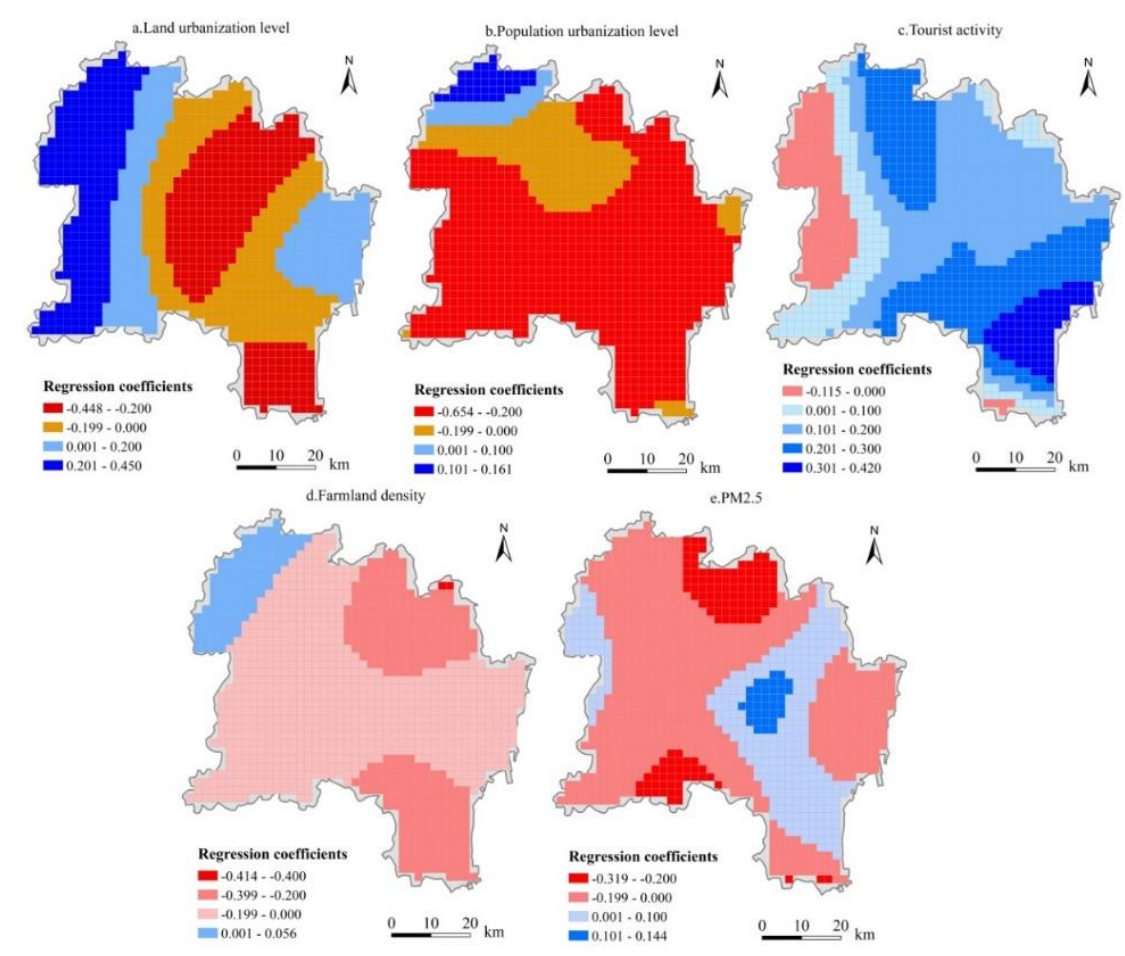

Figure 6. The spatial distribution of influencing factors regression coefficients based on GWR model 
(1) Land urbanization. From a local point of view, there are obvious characteristics of spatial heterogeneity in the intensity and direction of the impact of the land urbanization on ecosystem health in different regions. From a detailed point of view, there is a negative relationship between land urbanization and ecosystem health in the central mountain area of the study area, that is, the lower the level of land urbanization, the higher the level of ecosystem health (Fig. 6). There is a strong positive relationship between land urbanization and ecosystem health in the western agricultural area of the study area, and a weak positive relationship between land urbanization and ecosystem health in the eastern area of Donggang county.

(2) Population urbanization. From a local point of view, the level of population urbanization has a negative impact on the ecosystem health of most regions, while a few areas have a positive impact, showing obvious characteristics of spatial heterogeneity. In detail, the level of population urbanization has a positive impact on the northwest of the study area, while a negative impact on other areas (Fig. 6). Combined with Figure 2, we can see that the northwest of the study area was a typical agricultural area, the level of ecosystem health and population urbanization was low, so there was a positive relationship between the ecosystem health and population urbanization.

(3) Tourism activities. From a local point of view, tourism activities have a positive impact on the ecosystem health of most regions, a few areas have a negative impact, and the impact intensity (regression coefficient) shows obvious characteristics of spatial heterogeneity. From a detailed point of view, there is a positive relationship between the level of ecosystem health and the density of tourism activities in the central (mountainous area) and eastern (coastal ecological landscape zone) (Fig. 6). In some western areas (agricultural areas and built-up areas of county), there was a negative relationship between tourism activity density and ecosystem health level. There is a positive relationship between the density of tourism activities and the ecosystem health level of the central (mountainous area) and eastern (coastal landscape zone). This is mainly because there are a large number of eco-landscape tourist spots, such as forest parks, wetland parks, botanical gardens and ecological gardens in the central (mountainous) and eastern (coastal landscape zones).

(4) Agricultural activities. From a local point of view, the intensity of agricultural activities has a negative impact on the ecosystem health of most areas, a few areas have a positive impact, the impact intensity shows obvious characteristics of spatial heterogeneity. From a detailed point of view, the intensity of agricultural activities has a negative impact on ecosystem health in most east-central regions (Fig. 6). Among them, the western region has higher agricultural activity intensity, but has lower ecosystem health level; The central and northeastern mountainous areas have lower levels of agricultural activity, but has higher ecosystem health level. Agricultural activities have a negative impact on regional ecosystem health by changing surface cover and destroying the structure and function of ecological landscape.

(5) Environmental pollution. From a local point of view, the intensity and direction of the impact of PM2.5 concentration on regional ecosystem health shows obvious characteristics of spatial heterogeneity. In detail, there was a negative relationship between PM2.5 concentration (higher) and ecosystem health level (lower) in the builtup areas of two counties and two districts in Rizhao City (Fig. 6), indicating that environmental pollution was also one of the leading factors affecting regional ecosystem health. There was a weak positive correlation between ecosystem health level 
and environmental pollution level (PM2.5 concentration) in western border area (agricultural area) and central basin (agricultural area and residential area).

\section{Discussion}

\section{Comparison with Previous Studies}

In the analysis result of influencing factors, land urbanization and population urbanization have significant negative effects on ecosystem health in the study area, which was consistent with the results of Xiao et al. (2020). The density of tourist spots has a significant positive impact on the ecosystem health of the study area, which was different from the results of Jin et al. (2017). This was mainly because the density of tourist attractions used in this study can only reflect the indirect impact of tourism development activities on ecosystem health to a certain extent, but cannot reflect the interference and impact of population flow and related industries on ecosystem health. However, it was undeniable that our choice of tourism activity indicators is a useful attempt on the basis of considering the availability of data. The intensity of agricultural activities has a significant negative impact on regional ecosystem health, which was consistent with the results of Wardropper et al. (2020) and Diaz-Maroto et al. (2018). Wardropper et al. (2020) and Diaz-Maroto et al. (2018) pointed out that agricultural activities have an important impact on forest landscape, ecosystem services and natural ecosystems. Environmental pollution has a significant negative impact on ecosystem health in the study area, which is consistent with the results of Souza et al. (2021). Souza et al. (2021) pointed out that atmospheric particulate matter has a negative impact on vegetation and water sources, which in turn has a negative impact on aquatic ecosystems and ecosystem services.

\section{Implications for Eco-Management}

The spatio-temporal assessment of ecosystem health based on grid scale can not only reveal the temporal and spatial distribution and agglomeration characteristics of ecosystem health, but also find the differences of the main influencing factors of internal units based on the analysis of influencing factors, and identify different regional ecological risk factors, which can provide reference for the formulation of detailed regional eco-management policies. Our research results make clear the spatial differences and local influencing factors of ecosystem health, so we can take targeted ecological protection and ecological management measures according to the actual situation of different areas.

In this study, the rapid development of tourism has driven the catering industry, accommodation industry, and related infrastructure construction, and then promoted the rapid development of land urbanization and population urbanization. The built-up areas of districts and counties, central intermountain basins and coastal landscape belts were the main areas of drastic changes in land cover caused by the development of tourism, and ecological management measures should be implemented in these areas. Specifically, in the built-up areas of districts and counties, through the formulation of detailed urban land use planning to reasonably control the speed of urban expansion and optimize the land use structure to improve land use efficiency, and then reduce the destruction of land cover. In the central intermountain basin and coastal landscape belt, it is necessary to draw red lines for ecological protection of important ecological 
landscapes such as forests, grasslands and wetlands, and strictly examine and approve tourism development projects, real estate development projects, and infrastructure construction projects.

The areas with high intensity of agricultural activities include the western plain and the surrounding areas. Among them, In the western plain agricultural areas, on the basis of controlling the red line of cultivated land, it is necessary to prohibit the expansion of farmland in the surrounding areas such as important wetlands, rivers and lakes, reduce the use of pesticides and chemical fertilizers to prevent harm to water sources and soil, and prohibit the burning of crop straw to prevent air pollution. In the mountainous slopes of the northeast, government management departments should guide farmers to return farmland to forests to prevent soil erosion and damage to the ecological landscape, and encourage the development of ecological agriculture such as fruit planting.

The areas with serious environmental pollution include the surrounding areas of the established area, the central basin and the western agricultural region. Among them, the surrounding areas of the built-up area and the southern part of the central basin should be eliminated and the external transfer of heavy polluting enterprises should be guided. The environmental pollution sources in the western agricultural region mainly include particulate matter produced by burning crop straw and waste gas produced by the use of non-clean energy in daily life. Relevant departments should actively guide rural residents to use cleaner energy on the basis of subsidies.

\section{Limitations and Future Work}

The setting of index weight is very important to the result of ecosystem health evaluation. In this study, the ecosystem health assessment model based on VORS framework also has potential uncertainty, in which the weight of evaluation factors is one of the main factors that cause controversy and lead to uncertain results. In addition, all other parameters influence and interact with each other in a practical system, and the sensitivity index of a single parameter will be affected by the set values of other parameters, that is, the coupling between parameters has an indirect impact on the results of the model (Saltelli et al., 1999; Zhang et al., 2014). Therefore, in the future research, we also need to analyze the global sensitivity and uncertainty of the model in order to verify the reliability of the evaluation model as a whole.

In terms of the influencing factors of ecosystem health, our research still has the following two shortcomings: first, due to the difficulty of quantifying human activity factors and the complexity of the mechanism of human activities on ecosystem health, the human activity factors selected in this study may not be comprehensive enough, such as water pollution and soil pollution, eco-environmental protection policies and measures. Second, there are extremely complex interactions among the influencing factors of ecosystem health. Therefore, it is very important to clarify the complex mechanism of action among multiple factors and its impact mechanism on ecosystem health, which should be paid attention to in future research.

\section{Conclusion}

Based on multi-source data and GIS and RS techniques, this study quantitatively analyzed the spatio-temporal pattern of ecosystem health in Rizhao by using VORS model. Then, the geographically weighted regression model was used to explore the 
spatial heterogeneity of the impact of human activity factors on ecosystem health. The main conclusions are as follows:

(1) The ecosystem health level of Rizhao showed a significant spatial differentiation pattern from 1990 to 2018. The low-value areas were mainly distributed in the northwestern plain agricultural areas, the central basins, and the built-up areas in the southeast coast. The high-value areas were mainly distributed in the central mountainous and hilly areas and the eco-landscape belt in the southeast coast.

(2) From the spatial change trend of ecosystem health level, the overall ecosystem health level of Rizhao City showed a trend of first decline and then rise from 1990 to 2018. The areas with great changes in health level were mainly distributed in the western agricultural areas, the surrounding areas of urban build-up area, the central basin, and some coastal eco-landscape belts.

(3) The high-high agglomeration areas of ecosystem health were mainly distributed in the central mountainous areas and the northeast coastal areas. The low-low agglomeration areas were distributed in the urban built-up areas, plain agricultural areas and central basins in the northwest. During the study period, the high-high agglomeration areas (urban built-up area and central basin) has a trend of expansion, while the low-low agglomeration area of the central part has a tendency to expand to the northeast coastal area.

(4) The analysis of driving factors shows that land urbanization, population urbanization, tourism activities, agricultural activities and environmental pollution all had significant impacts on ecosystem health. From the spatial heterogeneity of driving factors, the impact intensity and direction of driving factors on ecosystem health in the study area have obvious spatial heterogeneity characteristics. Land urbanization, population urbanization, tourism activities and environmental pollution are closely related. The rapid development of tourism drives the catering industry, accommodation industry and other related services, thus promoting the rapid development of land urbanization and population urbanization, and at the same time causing certain environmental pollution. The edge of the built-up area, the central mountain basin and the coastal landscape belt are the main areas affected by the complex effects of land urbanization, population urbanization and tourism activities development. In these areas, detailed land use planning can be made to control the speed of urban expansion, optimize the land use structure and improve the land use efficiency. Agricultural activities and environmental pollution have a significant negative impact on the ecosystem health level in the agricultural plain and surrounding built-up areas. Agricultural areas on the plain need to strictly control the red line of cultivated land, and prohibit the destruction of wetlands and the reclamation of land from lakes. The mountainous areas and sloping areas in central China should guide farmers to return farmland to forests to prevent soil erosion and ecological landscape damage, and encourage the development of ecological agriculture such as fruit and tree planting.

Funding. This research was funded by the Natural Science Foundation of Henan Province (202300410078), the Key Scientific Research Projects of Colleges and Universities in Henan Province (20A170002) and the Humanities and Social Sciences Research Project of Henan Education Department (2020-ZZJH-076).

Conflicts of Interests. The authors declare no conflict of interests. 


\section{REFERENCES}

[1] Asumadu-Sarkodie, S., Owusu, P. A. (2017): The impact of energy, agriculture, macroeconomic and human-induced indicators on environmental pollution: evidence from Ghana. - Environmental Science and Pollution Research 24: 6622-6633.

[2] Bae, D. Y., Kumar, H. K., Han, J. H. (2010): Integrative ecological health assessments of an acid mine stream and in situ pilot tests for wastewater treatments. - Ecological Engineering 36: 653-663.

[3] Bebianno, M. J., Pereira, C. G., Rey, F., Cravo, A., Duarte, D., D’Errico, G., Regoli, F. (2015): Integrated approach to assess ecosystem health in harbor areas. - Science of the Total Environment 514: 92-107.

[4] Brunsdon, C., Fotheringham, A. S., Charlton, M. (1999): Some notes on parametric significance tests for geographically weighted regression. - Journal of regional Sciences 39: 497-524.

[5] Cao, W., Huang, L., Xiao, T., Wu, D. (2019): Effects of human activities on the ecosystems of China's National Nature Reserves. - Acta Ecologica Sinica 39: 1338-1350.

[6] Chase, J. M., Blowes, S. A., Knight, T. M., Gerstner, K., May, F. (2020): Ecosystem decay exacerbates biodiversity loss with habitat loss. - Nature 584: 238-262.

[7] Chen, J., Liang, G. F., Ding, S. Y. (2012): Landscape connectivity analysis for the forest landscape restoration: a case study of Gongyi City. - Acta Ecologica Sinica 32: 37733781.

[8] Chi, Y., Zheng, W., Shi, H. H., Sun, J. K., Fu, Z. Y. (2018): Spatial heterogeneity of estuarine wetland ecosystem health influenced by complex natural and anthropogenic factors. - Science of the Total Environment 634: 1445-1462.

[9] Costanza, R., D'arge, R., Groot, R. D., Farber, S., Grasso, M., Hannon, B., Limburg, K., Naeem, S., O’Neill, R. V., Paruelo, J., Raskin, R. G., Sutton, P., van den Belt, M. (1997): The value of the world's ecosystem services and natural capital. - Nature 387: 253-260.

[10] Costanza, R., Mageau, M. (1999): What is a healthy ecosystem? - Aquatic ecology 33: $105-115$.

[11] Costanza, R. (2012): Ecosystem health and ecological engineering. - Ecological Engineering 45: 24-29.

[12] Costanza, R., Groot, R. D., Braat, L., Kubiszewski, I., Fioramontid, L., Sutton, P., Farber, S., Grasso, M. (2017): Twenty years of ecosystem services: How far have we come and how far do we still need to go? - Ecosystem services 28: 1-16.

[13] Diaz-Maroto, I. J., Diaz-Maroto, M. C. (2018): Changes in forest landscape due to agricultural activities and their influence on natural ecosystems: the eastern Galician mountains. Change and Adaptation. - Change and Adaptation in Socio-Ecological Systems 4: 1-6.

[14] Dou, Q., Zhang, Z. Y. (2019): Analysis on Environmental Pollution in China's Coastal Ecosystem. - Journal of Resources and Ecology 10: 424-431.

[15] Guo, C. B., Chen, Y. S., Li, W., Xie, S. G., Lek, S., Li, Z. J. (2018): Food web structure and ecosystem properties of the largest impounded lake along the eastern route of China's South-to-North Water Diversion Project. - Ecological Informatics 43: 174-184.

[16] Haddad, N. M., Brudvig, L. A., Clobert, J., Davies, K. F., Gonzalez, A., Holt, R. D. (2015): Habitat fragmentation and its lasting impact on Earth's ecosystems. - Science Advances 1: e1500052.

[17] Häder, D. P., Banaszak, A. T., Villafañe, V. E., Narvarte, M. A., González, R. A., Helbling, E. W. (2020): Anthropogenic pollution of aquatic ecosystems: Emerging problems with global implications. - Science of the Total Environment 713: 136586.

[18] He, J. H., Pan, Z. Z., Liu, D. F., Guo, X. N. (2019): Exploring the regional differences of ecosystem health and its driving factors in China. - Science of the Total Environment 673: 553-564. 
[19] Hu, K. H., Zhang, Z., Gao, M., Lu, Y. J. (2020): Variations in vegetation cover and natural factors of provinces in China along Silk Road Economic Belt during 2000-2018. Transactions of the Chinese Society of Agricultural Engineering (Transactions of the CSAE) 36: 148-157.

[20] Jin, Y. Z., Zheng, Z. X., Chang, M. H., Jia, J. C., Wang, J. Q., Ren, L. (2017): Control measures and effect of tourism activities on grassland vegetation and soil environment. Pratacultural Science 34: 310-320.

[21] Jin, K., Wang, F., Han, J. Q., Shi, S. Y., Ding, W. B. (2020): Contribution of climatic change and human activities to vegetation NDVI change over China during 1982-2015. Acta Geographica Sinica 75: 961-974.

[22] Kang, P., Chen, W. P., Hou, Y., Li, Y. Z. (2018): Linking ecosystem services and ecosystem health to ecological risk assessment: a case study of the Beijing-Tianjin-Hebei urban agglomeration. - Science of the Total Environment 636: 1442-1454.

[23] Khim, J. S. (2017): The Yellow Sea ecosystem: Pollution, ecosystem threats, and environmental health. - Chemosphere 182: 794-796.

[24] Li, X. D. (2011): A Study on Environmental Pollution of Agriculture and Countermeasures under the Double Failure. - Energy Procedia 5: 204-208.

[25] Li, Y. S. (2020): Management Model of the Coordinated Development of the Coastal Ecological Environment and Rural Tourism Economy. - Journal of Coastal Research 106: 53-56.

[26] Liao, C. J., Yue, Y. M., Wang, K. L., Fensholtd, R., Tong, X. W., Brandt, M. (2018): Ecological restoration enhances ecosystem health in the karst regions of southwest China. - Ecological Indicators 90: 416-425.

[27] Ling, H. B., Xu, H. L., Guo, B., Deng, X. Y., Zhang, P., Wang, X. Y. (2019): Regulating water disturbance for mitigating drought stress to conserve and restore a desert riparian forest ecosystem. - Journal of Hydrology 572: 659-670.

[28] Liu, D. L., Hao, S. L. (2017): Ecosystem health assessment at county-scale using the pressure-state-response framework on the Loess Plateau, China. - International Journal of Environmental Research and Public Health 14: 2.

[29] Logana, M., Hu, Z. Y., Brinkmana, R., Sun, S., Sun, X. X., Schaffelke, B. (2020): Ecosystem health report cards: An overview of frameworks and analytical methodologies. - Ecological Indicators 113: 105834.

[30] Lu, W., Su, M., Zhang, Y., Yang, Z., Chen, B., Liu, G. (2014): Assessment of energy security in China based on ecological network analysis: a perspective from the security of crude oil supply. - Energy Policy 74: 406-413.

[31] Lu, X. L., Liang, G. F., Tang, Q., Ding, S. Y., Li, Q. X., Zhang, X. Q. (2014): Plant species of the non-agricultural habitats in the lower reaches of the Yellow River plain agro-landscape. - Acta Ecologica Sinica 34: 789-797.

[32] Meng, L. R., Huang, J., Dong, J. H. (2018): Assessment of rural ecosystem health and type classification in Jiangsu province, China. - Science of the Total Environment 615: 1218-1228.

[33] Millennium Ecosystem Assessment. (2005): Ecosystem and Human Well-being: biodiversity Synthesis. - World Resources Institute, 2p.

[34] Mirsanjari, M. M., Zarandian, A., Mohammadyari, F., Visockiene, J. S. (2020): Investigation of the impacts of urban vegetation loss on the ecosystem service of air pollution mitigation in Karaj metropolis, Iran. - Environmental Monitoring and Assessment 192: 1-23.

[35] Paoletti, E., Feng, Z. Z., Marco, A. D., Hoshika, Y., Harmens, H., Agathokleous, E., Domingos, M., Mills, G., Sicard, P., Zhang, L., Carrari, E. (2020): Challenges, gaps and opportunities in investigating the interactions of ozone pollution and plant ecosystems. Science of the Total Environment 709: 136118. 
[36] Peng, J., Liu, Y. X., Li, T. Y., Wu, J. S. (2017): Regional ecosystem health response to rural land use change: a case study in Lijiang City, China. - Ecological Indicators 72: 399-410.

[37] Pimm, S. L., Jenkins, C. N., Abell, R., Brooks, J. L., Gittleman, L. N., Joppa, P. H. (2014): The biodiversity of species and their rates of extinction, distribution, and protection. - Science 344: 1246752-1246752.

[38] Qin, X. N., Cheng, Y. (2019): Evaluation and Type Classification on Chinese Tourist Urban Ecological Security System: Based on the Network DEA Model with Node Weight. - Scientia Geographica Sinica 39: 156-163.

[39] Rapport, D. J., Costanza, R., McMichael, A. J. (1998): Assessing ecosystem health. Trends in ecology \& evolution 13: 397-402.

[40] Rapport, D. J., Bohn, G., Buck, I. D., Cairns, J., Costanza, R., Karr, J. R., Kruijf, H. D., Levins, R., McMichael, A. J., Nielsen, N. O., Whitford, W. G. (1999): Ecosystem health: the concept, the ISEH, and the important tasks ahead. - Ecosystem Health 5: 82-90.

[41] Rapport, D. J., Maffi, L. (2011): Eco-cultural health, global health, and sustainability. Ecological Research 26: 1039-1049.

[42] Saltelli, A., Tarantola, S., Chan, K. P. S. (1999): A quantitative model-independent method for global sensitivity analysis of model output. - Technometrics 41: 39-56.

[43] Santos, J. E., Nogueira, F., Pires, J. S., Obara, A. T., Pires, A. M. (2001): The value of the Ecological Station of Jataí's ecosystem services and natural capital. - Revista Brasileira de Biologia 61: 171.

[44] Shen, Q., Ma, Y. (2020): Did water diversion projects lead to sustainable ecological restoration in arid endorheic basins? Lessons from long-term changes of multiple ecosystem indicators in the lower Heihe River Basin. - Science of the Total Environment 701: 134785.

[45] Shen, W., Zheng, Z. C., Qin, Y. C., Li, Y. (2020): Spatiotemporal Characteristics and Driving Force of Ecosystem Health in an Important Ecological Function Region in China. - International Journal of Environmental Research and Public Health 17: 5075.

[46] Shi, Y., Han, R., Guo, L. (2020): Temporal Spatial Distribution of Ecosystem Health and Its Response to Human Interference Based on Different Terrain Gradients: A Case Study in Gannan, China. - Sustainability 12: 1773.

[47] Souza, I. C., Morozesk, M., Mansano, A. S., Mendes, V. A. S., Azevedo, V. C., Matsumoto, S. T., Elliott, M., Monferrán, M. V., Wunderlin, D. A., Fernandes, M. N. (2021): Atmospheric particulate matter from an industrial area as a source of metal nanoparticle contamination in aquatic ecosystems. - Science of the Total Environment 753: 141976.

[48] Su, M. R., Fath, B. D., Yang, Z. F. (2010): Urban ecosystem health assessment: A review. - Science of the Total Environment 408: 2425-2434.

[49] Su, M. R., Xie, H., Yue, W. C., Zhang, L. X., Yang, Z. F., Chen, S. H. (2019): Urban ecosystem health evaluation for typical Chinese cities along the Belt and Road. Ecological Indicators 101: 572-582.

[50] Sun, T. T., Lin, W. P., Chen, G. S., Guo, P. P., Zeng, Y. (2016): Wetland ecosystem health assessment through integrating remote sensing and inventory data with an assessment model for the Hangzhou Bay, China. - Science of the Total Environment 566: 627-640.

[51] Sun, Q., Wen, Z. (2019): Effect of Tourism Development on the Urban Soil and Ecological Environment. - Journal of Shandong Agricultural University (Natural Science Edition) 50: 1065-1070.

[52] Sun, B. D., Tang, J. C., Yu, D. H., Song, Z. W., Wang, P. G. (2019): Ecosystem health assessment: A PSR analysis combining AHP and FCE methods for Jiaozhou Bay, China. - Ocean \& Coastal Management 168: 41-50. 
[53] Sun, Q., Zhang, N. C., Liu, Z., Liao, B. (2020): Tourism resources and carrying capacity of scenic tourism areas based on forest ecological environment. - Southern Forests: a Journal of Forest Science 82: 10-14.

[54] Wang, C., Qu, A. Y., Wang, P. F., Hou, J. (2013): Estuarine ecosystem health assessment based on the DPSIR framework: A case of the Yangtze Estuary, China. - Journal of Coastal Research 65: 1236-1241.

[55] Wardropper, C. B., Mase, A. S., Qiu, J., Kohl, P., Booth, E. G., Rissman, A. R. (2020): Ecological worldview, agricultural or natural resource-based activities, and geography affect perceived importance of ecosystem services. - Landscape and Urban Planning 197: 103768.

[56] Wu, Z., Dai, E. F., Lin, M. Z. (2018): Simulating the effect of climate change and human activities on the forest ecosystem in the hilly red soil region of southern China: A case study in Taihe county, Jiangxi province. - Geographical Research 37: 2141-2152.

[57] Xiao, R., Liu, Y., Fei, X. F., Yu, W. X., Zhang, Z. H., Meng, Q. X. (2019): Ecosystem health assessment: A comprehensive and detailed analysis of the case study in coastal metropolitan region, eastern China. - Ecological Indicators 98: 363-376.

[58] Xiao, Y., Guo, L., Sang, W. G. (2020): Impact of Fast Urbanization on Ecosystem Health in Mountainous Regions of Southwest China. - International Journal of Environmental Research and Public Health 17: 826.

[59] Xie, G. D., Zhen, L., Lu, C. X., Xiao, Y., Chen, C. (2008): Expert knowledge based valuation method of ecosystem services in China. - Journal of Natural Resources 23: 911-919.

[60] Xie, G. D., Zhang, C. X., Zhang, L. M., Chen, W. H., Li, S. M. (2015): Improvement of the Evaluation Method for Ecosystem Service Value Based on Per Unit Area. - Journal of Natural Resources 30: 1243-1254.

[61] Xu, M. D., Li, J., Peng, J., Niu, J., Cao, L. (2010): Ecosystem health assessment based on RS and GIS. - Ecology and Environmental Sciences 19: 1809-1814.

[62] Xu, E. Q., Zhang, H. Q. (2013): Spatially-explicit sensitivity analysis for land suitability evaluation. - Applied Geography 45: 1-9.

[63] Yan, Y., Zhao, C. L., Wang, C. X., Shan, P., Zhang, Y. J., Wu, G. (2016): Ecosystem health assessment of the Liao River Basin upstream region based on ecosystem services. - Acta Ecologica Sinica 36: 294-300.

[64] Yang, Y., Liu, Y. (2014): Spatio-temporal analysis of urbanization and land and water resources efficiency of oasis cities in Tarim River Basin. - Journal of Geographical Sciences 25: 509-525.

[65] Zeng, C., Deng, X. Z., Xu, S., Wang, Y. T., Cui, J. X. (2016): An integrated approach for assessing the urban ecosystem health of megacities in China. - Cities 53: 110-119.

[66] Zhang, Z. M., Wang, X. Y., Li, M. T. (2014): Uncertainty analysis of WASP based on global sensitivity analysis method. - China Environmental Science 34: 1336-1346.

[67] Zhang, Y. L., Cao, F. (2015): Fine particulate matter (PM2.5) in China at a city level. Scientific Reports 5: 14884.

[68] Zhang, P. Y., Geng, W. L., Yang, D. (2020): Spatial-temporal evolution of land use and ecosystem service value in the Lower Reaches of the Yellow River Region. Transactions of the Chinese Society of Agricultural Engineering (Transactions of the CSAE) 36: 277-288. 